Sección uno: Ensayo

Educación y Exclusión social

\title{
Género y delincuencia: de la exclusión a la criminalización ${ }^{1}$
}

Gender and crime: from exclusión to criminalization

\author{
Maria Revelles Carrasco \\ Pfra. Dep. Derecho Internacional \\ Público,Penal y Procesal \\ maria.revelles@uca.es
}

\section{Resumen}

La desigualdad de poder entre hombres y mujeres, producto de una socialización dicotómica y jerárquica, que constituye el imaginario de la sociedad patriarcal, trae como consecuencia que la mujer se vea adscrita a unas conductas estereotipadas, de tal forma que al alejarse de ellas, se ven inmersas en un proceso de segregación con la subsiguiente marginalización y/o exclusión. El control social informal penetra de forma difusa pero eficaz en su cara opuesta y homóloga a la vez, el control social formal; y los comportamientos desarraigados del patriarcalismo sufren la metamorfosis de desviados a criminalizados. La reclusión en femenino no queda ajena a los (des)valores de esta sociedad: para la mujer la pena privativa de libertad es más dura y conlleva situaciones más discriminatorias que para el hombre, agravándose en el caso de mujeres extranjeras y mujeres gitanas. Pese a que las políticas de igualdad se van sucediendo, la interiorización del patriarcalismo es tan profunda que requiere estrategias educativas y sobre todo la deconstrucción del propio sistema.

Palabras clave: criminalización, cultura del control, delincuencia, exclusión, género.

\begin{abstract}
The inequality of power between men and women, the product of a dichotomous and hierarchical socialization, which constitutes the imaginary of patriarchal society, results in women being ascribed to stereotyped behaviors, so that by moving away from them, they are immersed in a process of segregation with the subsequent marginalization and/or exclusion. The informal social control penetrates in a diffuse but effective way in its opposite and
\end{abstract}

${ }^{1}$ Recibido: / /2018 Evaluado:/ /2018 Aceptado: 27/08/2018 
homologous face at the same time, formal social control, and the uprooted behaviors of patriarchy suffer the metamorphosis of deviant to criminalized. Female imprisonment is not alien to the (dis)values of this society: for women the penalty of imprisonment is harsher and involves more discriminatory situations than for men, aggravating in the case of foreign women and Roma women. Despite the fact that equality policies are happening, the internalization of patriarchy is so deep that it requires educational strategies and above all the deconstruction of the system itself.

Keywords: criminalization, culture of control, delinquency, exclusion, gender.

\section{El patriarcalismo: paradigma de estigmatización}

A través de los procesos de socialización se transmite en la sociedad la cultura, que constituye el cuerpo de normas, ideas, creencias y costumbres que rige los diversos grupos sociales (Malinowski, 1984, pp. 56-57). A partir de un medio natural preexistente, se construye un ambiente artificial por la cultura dada, en el que las personas deben adaptarse, convirtiéndose su comportamiento en homogéneo y previsible. Así, todo grupo social debe actuar acorde a estas normas, las cuales atribuyen los roles y funciones que cada uno de sus miembros deben cumplir. Quien se aparte de estas expectativas entra en un espacio de abyección y marginación, siendo calificados de desviados constituyendo esta atribución un auténtico estigma. Esta palabra, de origen griego, hacía referencia a signos corporales con los cuales se intentaba exhibir algo malo y poco habitual en el estatus moral de quien los presentaba (Goffman, 1998, p. 12).

Así pues, según el sistema de roles que caracteriza a la sociedad y las expectativas de un comportamiento conforme a estos roles, lleva a la distinción entre: identidad social virtual, como las características atribuidas en potencia al individuo; e identidad social real, como los atributos que de hecho le pertenecen a dicho individuo (Goffman, 1998, p. 12). El estigma constituye una discrepancia entre estas dos identidades y se constituye como una esencia profundamente desacreditadora, situándose entre estereotipo y atributo real (Goffman, 1998, p. 13). Los estigmas pueden hacer referencia a diferencias físicas, psíquicas o ideológicas. Frente a las personas estigmatizadas se hallan las personas normales, definiéndose como aquellas que no se apartan negativamente de las expectativas sociales, que no se desvían ni realizan conductas desviadas.

El juicio que produce la clasificación de ciertas conductas como desviadas, implica sobre todo un juicio moral, una oposición al código moral y convenciones dominantes (Coy y Martínez, 1988, p. 14, citando a Becker, 1971). Definiéndose la desviación como la transgresión de las reglas y normas vigentes (sean jurídicas o no) de una sociedad. Y se consideran desviados, quienes realizan dicha transgresión. A su vez Dinitz y cols. (1969, citado por Coy y Martínez, 1988, p. 15) distingue entre cinco tipos de desviados: 1) los contrarios al canon físico o intelectual; 2) los que quebrantan las normas religiosas o ideológicas; 3) los que infringen las normas jurídicas; 4) los enfermos mentales; y 5) los que rechazan los valores culturales. Aunque también hay autores que distinguen entre personas desviadas y personas desviantes, siendo estos últimos, aquellos que la sociedad etiqueta como 
tales, pero más por cumplir determinadas características que, por ejecutar comportamientos desviados (Coy y Martínez, 1988, p. 15).

La teoría del estigma emerge como una teoría de discriminación, como una ideología para explicar la inferioridad de ciertos sujetos o clase de sujetos, racionalizando y naturalizando auténticas falacias. El ejemplo más clamoroso es el patriarcalismo, que proclama la superioridad del hombre sobre la mujer basándose en agentes biológicos. Es la teoría de poder más antigua que existe (Engels, 2013). Bajo esta premisa, la mujer aparece como un ser estigmatizado, donde la simbología ha cursado un papel fundamental. Las consecuencias de la estigmatización son devastadoras, la persona estigmatizada pierde su autoestima e incluso busca la transformación del yo a través de un aprendizaje distorsionado (Goffman, 1998, p. 19). Así, la mujer llega a interiorizar las propuestas patriarcales.

Pero tal y como señala Coy y Martínez (1988, p. 14) "no nos encontramos ante una realidad en sí, sino ante una realidad construida socialmente, en cuanto que tales comportamientos han sido definidos en función de normas variables en el espacio y en el tiempo". Siguiendo con este ejercicio de exclusión y segregación, se afirma desde los discursos legitimadores de la teoría del estigma, que la desviación, pese a su carácter anómalo, no siempre representa la disfuncionalidad. De hecho, la desviación, afirman, puede cumplir la función de poner al descubierto normas ambivalentes, que solo se delimitan a raíz de la misma y por ello otorgan mayor cohesión al grupo. O bien, forma parte de una dicotomía maldad-bondad y sirve para conferir relevancia a su oponente, la bondad. Pero la función más importante, es la capacidad de aunar al grupo, en su lucha contra la desviación. Esto recuerda a las estrategias de manipulación totalitaristas reflejadas en "1984", concretamente a los dos minutos de odio diario que los ciudadanos tienen que dedicar contra el enemigo (Orwell, 2010).

En contra del prisma de la estigmatización de las mujeres y la consideración como conducta desviada el alejamiento de las imposiciones y roles de género por parte de éstas, se revelan feministas disidentes como Cristina Hoff Sommers y Camille Plagia, que rechazan "la actitud victimista del feminismo, que presenta a la mujer como un ser vulnerable, siempre en peligro y sometido a la dominación masculina, y al hombre como un ser violento, un agresor en potencia, que mantiene oprimida a la mujer en todos los aspectos de las esferas pública y privada". Otra actitud para desterrar, manifiestan estas autoras, es "el resentimiento y el giro ginecéntrico que se ha apoderado de la perspectiva feminista", como estrategias de manipulación, para presentar al hombre verdugo y a la mujer víctima (León-Mejía, 2006, p. 23).

\subsection{La dicotomía del género: aceptación versus exclusión (y marginación)}

La sociedad heteropatriarcal ha construido las identidades de género en función de la premisa de que el hombre es un sujeto que cumple con las expectativas del género humano, es un ser asertivo, ambicioso, fuerte y capaz; y de que la mujer es un ser inferior, necesitado y dependiente. Bajo esta mentira, las mujeres devienen en sujetos estigmatizados, cuya falta de reconocimiento, según afirma Juliano (2004, p. 26) "actúa como elemento de subordinación social y de explotación económica". Se justifica esta explotación, tanto reproductiva como productiva, en cuanto que los roles asignados a la mujer giran en torno a la denominada ética del cuidado, que manifiesta que para la mujer el cuidado de los demás es algo innato e 
inherente a su naturaleza, y por ello no constituye un trabajo para la misma, sino una autocomplacencia de su necesidad de servir.

Pero la construcción identitaria de la mujer como ser estigmatizado, se extiende no sólo a los aspectos económicos sino también y sobre todo a los aspectos sociales, sufriendo un proceso de segregación a través de dos mecanismos: la marginación y la exclusión social. La marginación incluye a la persona en el sistema social, pero desde posiciones periféricas, no se prescinde de ellas pero no se le reconoce poder legítimo, ni prestigio (Juliano, 2004, p. 28, citando a San Román, 1990). La exclusión implica un paso más, "no se les reconoce a las personas afectadas la capacidad de actuar, decidir o evaluar por sí mismas" (Juliano, 2004, p. 29). El concepto de exclusión es más amplio que el de pobreza, ya que "implica procesos más complejos, incluye con preferencia grupos sociales y es multidimensional" (Juliano, 2004, p. 27, citando a González Rodríguez, 2000, p. 16). De la marginalización y la exclusión a la criminalización va un paso, el del "señalamiento social de los indeseables a través de la prensa y la formación de una corriente de opinión partidaria de aplicarles toda la severidad de la ley" (Juliano, 2004, p. 30).

Tanto la mujer como el hombre son construcciones sociales (Butler, 2007). De hecho, el proceso de construcción social del hombre es una "operación de dos caras: de una parte, se reducen las diferencias personales potenciales entre los individuos varones tratando de uniformizar a estos en torno a un modelo de sujeto masculino; y de otra parte, se trata de aumentar las diferencias que todos los varones podrían tener con las mujeres" (Marqués, 1990, p. 40). El hombre y la mujer son una determinada combinación de posibilidades humanas. Salvo que al hombre de un lado, se le ha quitado diversas posibilidades -que se le otorga a la mujer- a la vez que se les ha fomentado otras -que se le quita a la mujer-, y se le ha conferido una consigna básica que interioriza para identificarse como varón. Y de otro lado, a la mujer se le fomenta las posibilidades quitadas al hombre y se le veta las posibilidades dadas al hombre, a la que también se le da una consigna que interioriza para identificarse como mujer (Marqués, 1990, p. 42).

En consecuencia, mujeres y hombres no son sujetos diferentes sino que responden a un distinto proceso de socialización del que la sociedad patriarcal se ha encargado de inculcar, bajo el prisma de la dominación del hombre sobre la mujer. El sometimiento del hombre a este papel de opresor comporta dos sentimientos contradictorios para él mismo. Se siente bien con el sexo que le ha correspondido, pertenece al colectivo importante, es el jefe. Pero también puede sentir angustia por no cumplir las expectativas que su sexo requiere. Marqués (1990, p. 53) señala, que para el varón serlo es importante pero también siente que debe ser importante. En base a cómo viva esta afirmación será un varón en propiedad, un opresor tranquilo y seguro; o será un varón en precario, que puede ser un sujeto traumáticamente conflictivo con las mujeres, por esa necesidad constante de responder a unas expectativas que les son en principio utópicas, porque corresponden a un imaginario irreal. Para mantener la opresión y su supuesta superioridad sobre la mujer, a título individual, el hombre se vale de diversas estrategias interpersonales denominadas micromachismos, que "pueden no parecer muy dañinas, pero su poder, devastador a veces, se ejerce por la reiteración a través del tiempo" (Bonino, 1999, p. 197). Se distingue entre: micromachismos coercitivos, en los que el varón usa la fuerza moral, psíquica o económica para doblegar a la mujer; micromachismos encubiertos, en los que el hombre aprovecha la dependencia afectiva de la 
mujer para provocar en ella, de forma sutil, sentimientos de desvalimiento; y los micromachismos de crisis, que suelen utilizarse en momentos de aumento de poder de la mujer o pérdida de poder del hombre (Bonino, 1999, p. 197). Sin embargo, muchos hombres no responden a estos parámetros impuestos por el patriarcalismo, disienten con esta teoría de dominación, pero "pocas veces se convierte en discrepancia" (Marqués, 1990, p. 71); se quejan, critican el machismo, pero no toman partido de forma activa.

\section{La cultura del control}

Dentro del imaginario cultural amplio que reúne las características de una sociedad, se halla una subcultura del control, que puede ser formal o informal. Desde la socialización primaria hasta la socialización secundaria, nuestras conductas son debidas a las normas sociales y jurídicas que forman la cultura dominante de nuestro contexto. Las normas sociales son en mayor medida más estigmatizantes y gozan de una característica que las hace impermeables al cambio, o al menos muy difíciles de deconstruir, y es precisamente la normalización, que actúa como una tecnología de poder. Juliano (2004, p. 32) señala que son auténticas técnicas de manipulación, que Foucault denomina biopolíticas que procura la incorporación de los cuerpos en el ámbito productivo. He aquí el control social informal, que a pesar del (in) radican en ella mayor fuerza y formalidad, puesto que no pueden ser derogadas. Las normas jurídicas constituyen el control social formal, gozando de consecuencias jurídicas en caso de incumplimiento, y si pueden ser derogadas.

La subordinación de la mujer basada en la discriminación legal, social y laboral, se consiguió a lo largo de los siglos a través del control social formal: mecanismos de índole legal ejercidos por el poder coercitivo de los aparatos del Estado. Y de forma paralela, pero complementaria, a través del control social informal, plasmado en la presión ideológica como defensa de unos valores socioculturales determinados de división de las esferas (Nash, 1989, p. 152). No obstante, esta complementariedad no siempre se produce, "como en el caso del aborto, en el que los medios de control social informal lograron impedir la aplicación de este servicio en el momento de desaparición de los mecanismos formales de control" (Nash, 1989, p. 170). Los valores refridos, que relegaban a las mujeres a la esfera doméstica y al culto a la maternidad, defendiendo una mujer sumisa, abnegada y entregada; y al hombre a la esfera pública. Se predicaba para la mujer, el rechazo del trabajo extradoméstico y la aceptación de la supremacía del hombre (Nash, 1989, p. 162). Es muy significativa la extraordinaria incidencia de la Iglesia en el sistema escolar y educativo, que reforzó la socialización de la mujer según las coordenadas tradicionales de dedicación exclusiva a la familia. También el discurso médico actuaba como legitimador de la discriminación, de tal forma que si bien actualizó sus argumentos, finalmente defendía la segregación. Así, por ejemplo, el endocrino Gregorio Marañón promovió la teoría de que la mujer no es un ser inferior, sino diferente al hombre, cuya función primordial era la de ser madre y esposa (Nash, 1989, p. 160). Cualquier ruptura de este ideario suponía la transgresión, la desviación y por ende la estigmatización.

En la represión contra la mujer desviada actuaba el control social formal, el sistema punitivo con la consecuente pena, pero también el control social informal, etiquetando a las mujeres como mujeres públicas, esto es prostitutas, como se publicó en el Bando del Mariscal José María de Pastors (Nash, 1989, p. 158). Actualmente la Real Academia de la Lengua sigue considerando mujer pública como prostituta y por contra, prueba de un lenguaje ginope, al 
hombre público como hombre de negocios (Facio y Fries, 2005). Respecto al lenguaje sexista, García Meseguer (1977) afirmaba que la lengua española era profundamente sexista. Años posteriores en su obra ¿Es sexista la lengua española? (1994), matiza que: "el Diccionario de la Real Academia Española está lleno de definiciones sexistas. Prueba de ello son las diferencias de significado entre las palabras como "verdulero" y "verdulera" y "zorro" y "zorra". Ahora bien, "el diccionario no tiene culpa, ya que solo refleja los hechos de habla. Lo que se le puede censurar al diccionario es que a la hora de definir utilice palabras que son sexistas". Por otra parte, la consideración de la prostitución como un descrédito es otra forma de estigmatizar los derechos sexuales de la mujer.

A propósito de la sexualidad, uno de los grandes pilares, sino el que más del patriarcado, es la expropiación de los derechos reproductivos y sexuales de la mujer. En el caso de los derechos reproductivos, se ha configurado a la mujer como un simple receptáculo; y en el caso de los derechos sexuales se le ha privado de su derecho de autodeterminación sexual, relegando la libertad sexual de la mujer a un espacio constreñido, abyecto y siniestro. La cría del ser humano es la más indefensa del mundo animal, es la que más tarda en obtener alimento y valerse por sí misma. El papel de la madre de alimentarlo garantizaba la supervivencia de los seres humanos, además era la clave de la descendencia en una sociedad polígama. Este poder no quedó oculto por lo que, privándole de su libertad sexual y relegándola a un objeto sexual se le reprimía el poder que conllevaba (Lerner, 1990). Por ello, una de las claves de la deconstrucción del patriarcado pasa por conseguir que a las mujeres se las trate como seres humanos y no como objetos sexuales. "Hablar de la reputación de una mujer supone invocar su comportamiento sexual, pero hablar de la de un hombre supone hacer referencia a su personalidad, a sus éxitos y a su posición" (Lees, 1994, p. 5). Lees (1994) incide en la abismal diferencia en el tratamiento de la sexualidad para la joven y el joven en un estudio que realiza en diferentes institutos. Por ejemplo, la palabra "zorra" actúa como insulto para las chicas atenazando su valor moral, pero para los chicos no existe un equivalente. "El peso de la palabra zorra, empuja a las chicas a que canalicen su sexualidad hacia las vías legítimas del amor, que desemboca en el matrimonio" (Lees, 1994, p. 28). Las palabras zorra, puta, fresca, suelta, etc. que tanto se utiliza como insultos hacia las mujeres deberían desvestirse del insulto y del tono peyorativo y expropiarse del desprecio, siguiendo el ejemplo de la teoría queer propugnada por Butler.

La familia, como sistema de control informal y el derecho masculinista como sistema de control formal son dos de las instituciones fundamentales del sistema patriarcal. El Código Civil de 1889 establecía la obediencia de la mujer al marido (artículo 57). El marido era el administrador y el representante de la mujer (artículo 60). El poder marital quedaba reforzado con medidas punitivas. Aunque en los primeros Códigos Penales por ejemplo, la mayor prueba de la subyugación de la mujer, eran los tipos referidos al adulterio y a los crímenes pasionales. La pena del marido por matar al amante de la mujer era el destierro, pero si era la mujer la que mataba al amante del marido la pena era cadena perpetua. La infidelidad para la mujer suponía prisión y para el hombre estaba exenta de responsabilidad penal salvo que tuviera a "su concubina en la casa marital".

Desde los años noventa del siglo XX, con respecto a los medios de control social formal, se han logrado grandes avances normativos en aras de lograr la igualdad material entre hombres y mujeres. El Código Penal de 1995 recoge la punición de cualquier tipo de discriminación, 
así como recoge las reformas introducidas por la Ley 1/2004, de 28 de diciembre, de medidas integrales contra la violencia de género, por medio de las cuales se produce una protección tuitiva hacia la mujer contra conductas específicas delictivas de violencia de género. Esta norma recoge una heterogénea gama de derechos en los ámbitos penales, penitenciarios y procesales para la mujer víctima de violencia de género. La Ley 39/1999, de 5 de noviembre, para promover la conciliación de la vida familiar y laboral de las personas trabajadoras, afirma, en su Exposición de Motivos, la necesidad de regular un sistema de "cooperación y compromiso entre mujeres $y$ hombres que permita un reparto equilibrado de responsabilidades en la vida profesional y en la privada". Por su parte, la Ley Orgánica 3/2007, de 22 de marzo, para la igualdad efectiva entre mujeres y hombres, supone el reconocimiento explícito de la desigualdad sufrida por la mujer en todos los sectores de la vida y como los instrumentos legales -el ya citado control social formal- si bien se han corregido a lo largo de las décadas del último siglo y han ido eliminando progresivamente las desigualdades del derecho masculinista propio del patriarcado, no ha sido suficiente:

"El pleno reconocimiento de la igualdad formal ante la ley, aun habiendo comportado, sin duda, un paso decisivo, ha resultado ser insuficiente. La violencia de género, la discriminación salarial, la discriminación en las pensiones de viudedad, el mayor desempleo femenino, la todavía escasa presencia de las mujeres en puestos de responsabilidad política, social, cultural y económica, o los problemas de conciliación entre la vida personal, laboral y familiar muestran cómo la igualdad plena, efectiva, entre mujeres y hombres, aquella "perfecta igualdad que no admitiera poder ni privilegio para unos ni incapacidad para otros", en palabras escritas por John Stuart Mill hace casi 140 años, es todavía hoy una tarea pendiente que precisa de nuevos instrumentos jurídicos".

De hecho, queda un gran camino que recorrer aún. Pese a que las políticas de igualdad se van sucediendo con la consecuente reducción del control social formal, el control social informal se mantiene. La interiorización del patriarcalismo es tan profunda que requiere estrategias educativas y sobre todo la deconstrucción del propio sistema. En este sentido, La Ley 1/2004 de medidas integrales, en su Título I, artículos 3 a 16, incluye un mandato para que los poderes públicos establezcan medidas de prevención, sensibilización y detección de la violencia de género. Así, se ha llevado a cabo en todas las Comunidades Autónomas iniciativas para eliminar los estereotipos sexistas de los libros de texto y materiales educativos; se han elaborado guías específicas sobre lenguaje no sexista y llevan a cabo formaciones dirigidas a todos los agentes implicados. Así mismo, todas las Comunidades Autónomas realizan en mayor o menor medida formación del profesorado en materia de igualdad entre hombres y mujeres, coeducación, resolución pacífica de conflictos y prevención de la violencia de género. Destacan en Andalucía las Jornadas Provinciales de Formación en Igualdad de Género "Construyendo Igualdad", dirigidas a personal docente y personal técnico del Instituto Andaluz de la Mujer y Centros Municipales de Atención a la Mujer, que se vienen celebrando desde 2008. El programa "Coeducando" en la Comunidad Foral de Navarra de 4 años de duración, y el programa "+ Iguales” en Castilla y León, que desde el curso 2010 proporciona al profesorado herramientas para identificar desigualdades en el ámbito educativo, y para desarrollar una educación no sexista que proporcione valores de igualdad y contribuya a superar discriminaciones y prejuicios sociales (Ministerio de Sanidad, Asuntos Sociales e Igualdad, 2015:18). 


\section{De la desviación a la criminalización}

En el ámbito del control penal, los comportamientos desviados se elevan a la categoría de delitos. Según Christie (2004), "el delito no existe como una unidad estable, el concepto de delito es fácilmente adaptable a cualquier propósito de control... El delito es de libre uso". Las causas del comportamiento desviado en el ámbito de la justicia penal, se buscaron en un principio en anomalías biológicas del desviado, a través de teorías atávicas y de regresión (Lombroso, 1895). Posteriormente, las teorías de la criminalidad rechazaron las posturas biologicistas y se centraron en considerar que las causas de la delincuencia se hallaban en agentes externos al delincuente, en defectos de socialización tales como falta de oportunidades laborales, entornos de exclusión que les han privado de una educación, etc. En la actualidad, se ha revertido este rumbo criminológico, y el foco se ha trasladado al delito, alejándose del delincuente, así la teoría de la elección racional, se delinque, se desvía, por la oportunidad de delinquir.

La subordinación de los roles de género alcanza al delito, que relega al ámbito privado y actividades domésticas a la mujer, no teniendo éstas una presencia destacada en el mundo criminal. Así, el miedo a ser ellas la causa de la desestructuración de la familia, les frena para delinquir. En este sentido, Juliano (2009, p. 86) afirma que las mujeres desarrollan con cierto éxito estrategias alternativas al delito, estrategias de utilización preferentemente femeninas. Entre estas estrategias se encuentran: creación de redes de solidaridad y colaboración; aceptación de trabajos precarios sobre todo dentro del fenómeno de la feminización de los flujos migratorios; donación de óvulos y alquiler de vientre; contraer matrimonio, prostitución, etc. Saskia Sassen (citada por Juliano: 2009, p. 86) denomina a este conjunto de maniobras, feminización de la supervivencia. En el ámbito laboral, la feminización de la pobreza es un hecho evidente, las mujeres constituyen las dos terceras partes de los pobres del mundo, padecen mayor precariedad laboral y tienen mayor dificultad para acceder a puestos de trabajo bien remunerados.

El proceso de criminalización selecciona a las personas más desfavorecidas, desde el punto de vista socioeconómico. El control policial es más significativo y ya dentro del proceso judicial, en apariencia las prácticas son más neutras y rutinarias, pero tienden a desfavorecerlas (Equipo Barañí, 2001, p. 178).

\subsection{La criminalización de la prostitución}

Existe una categoría especial de delitos que se caracterizan porque son transacciones voluntarias en las puede mediar un componente económico (Lamo de Espinosa, 1989, p. 15). $\mathrm{Al}$ ser transacciones voluntarias, son delitos sin víctimas y sin un concreto e identificable bien jurídico protegido. Son delitos contra la moral, que según Lamo de Espinosa (1989, p. 18) "sanciona a los viciosos (como homosexuales, ebrios o toxicómanos), o sencillamente a quien facilite el vicio (prostitutas o prostitutos, aborteras y abortantes, productores o traficantes de pornografía), para erradicarlos". 
Uno de los grandes logros de la Modernidad en el ámbito del Derecho, fue la separación entre Derecho y Moral. La consideración del delito como pecado o vicio, es un anacronismo de etapas medievales. Si bien es cierto, que el delito es una construcción social, su necesidad se basa en lograr una convivencia pacífica en la sociedad, pero no debería ir más allá que buscar la protección de los bienes jurídicos recogidos en la Constitución o que puedan derivarse de ellos. Utilizar el poder coactivo del Derecho Penal, la violencia legítima del Estado, en aras de imponer unas pautas morales subjetivas constituye una vulneración de los Derechos Humanos, y nos retrotrae a la Ley 16/1970, de rehabilitación social (heredera de La ley de vagos y maleantes). Tal y como afirman Mestre y López (2006, p. 69) el hecho de que la Ley 16/1970 no estuviera incluida en el Código Penal no significa que no fuera una ley penalizadora. Según la Ley de peligrosidad social en su artículo 6.3, se establecía para quienes ejercieran la prostitución que tendrían que cumplir un internamiento en un centro de reeducación y sucesivamente prohibición de residencia en determinados lugares, prohibición de visitar determinados establecimientos y sumisión a los delegados del establecimiento. La prohibición de residencia y de entrada no tenía límite temporal. Esta pena en el Código Penal estaba prevista para delitos muy graves. Por tanto, la pregunta que realiza Lamo de Espinosa (1989, p. 21) ¿Es legítima la utilización del Derecho penal por parte del Estado para imponer una moral pública?" Debe ser contestada de forma rotunda con un no, ya que provoca una auténtica dictadura intelectual y vital. Coartar la libertad de las personas es terrible, pero crear personas desviantes a través de procesos de etiquetamiento, porque no cumplen unas determinadas características que cierta élite de poder considera como normales y adecuadas, es más terrible aún, ya que supone un genocidio de almas, pensamientos y sentimientos.

En la prostitución como delito sin víctima, se usa el estigma de la prostitución como técnica de persuasión y eso mantiene e intensifica el estigma, a expensas de las mujeres que hacen trabajo sexual (Rubin, 1986). La prostitución tiene un componente de género y de dimensión mundial que afecta a 40-42 millones de personas en todo el mundo, siendo la inmensa mayoría de las personas que se prostituyen mujeres y niñas y casi la totalidad de los usuarios hombres, siendo por tanto, causa y consecuencia de la desigualdad de género ( Resolución del Parlamento Europeo 2013/2013(INI), 2014).

Existen tres tipos de respuestas normativas a la prostitución: el prohibicionismo, el reglamentarismo actual y el abolicionismo (Mestre y López, 2006, p. 67). El prohibicionismo considera delito la prostitución, pues asevera que las prostitutas son mujeres desviadas y depravadas. El reglamentarismo argumenta que la prostitución es desviación, es un mal, es inmoral, pero necesaria; por ello, se debe permitir pero alejarla de la esfera pública y relegar a las mujeres que la ejercen a una zona privada, con controles sanitarios (únicamente para ellas pero no para los clientes). El reglamentarismo actual defiende el reconocimiento de la prostitución, como actividad económica, para así legalizar el dinero que mueve y reconocer derechos a las trabajadoras del sexo. Por su parte, el abolicionismo rechaza el reconocimiento o regulación de la prostitución, ya que sería legitimar la explotación y la dominación de las mujeres por parte de los hombres. Esta última postura rechaza la propuesta del reglamentarismo de considerar esta actividad como una transacción libre entre adultos, pues "el consentimiento supuesto de ellas es en realidad coerción patriarcal (Paterman, 1996, p. 221, Rubio, p. 2008, en Mestre y López, 2006, p. 86). 
En 2005, el Comité Internacional por los derechos de las trabajadoras del sexo en Europa, reunido en Bruselas, emitió un listado de recomendaciones, entre las que incluye: recibir apoyo institucional para la autorganización de las trabajadoras; recibir apoyo y tutela judicial en caso de violencia; reconocer que los derechos de las trabajadoras del sexo son derechos humanos; y reconocer que el trabajo sexual requiere de los mismos derechos que otros trabajos.

\section{De la criminalización a la reclusión}

\subsection{El internamiento}

En muchos casos, las personas estigmatizadas son apartadas de la sociedad en instituciones denominadas totales, que con su tendencia totalizadora se oponen a la interacción social con el exterior; y se clasifican en cinco grupos: hogares para personas incapaces e inofensivas; hogares para personas incapaces pero que constituyen una amenaza involuntaria para la sociedad; prisiones; instituciones de carácter laboral (cuarteles, barcos, etc.); y refugios del mundo (monasterios, abadías, etc.) (Goffman, 1972, p. 18). Las instituciones totales suponen una ruptura de la vida ordinaria, desarrollándose todos los aspectos de la misma -ocio, trabajo y descanso- en el mismo lugar, de forma programada y bajo la misma autoridad; en compañía de otrxs estigmatizados mediante un sistema de normas formales explícitas (Goffman, 1972, pp. 19-20). Pero la característica específica que define estas instituciones se halla en "el manejo de muchas necesidades humanas mediante la organización burocrática de conglomerados humanos" (Goffman, 1972, p. 20). De esta afirmación se extrae una obvia consecuencia: existen dos grupos bien diferenciados, los internos y el personal supervisor cuya función es la vigilancia de los internos. Grupos que no están exentos de representaciones estereotipadas, que dan lugar en algunos casos, a situaciones indeseables.

En el ordenamiento jurídico español, la pena privativa de libertad, el internamiento en los centros penitenciarios de los condenados por un delito, debe cumplir la finalidad de la rehabilitación social (ex artículo 25.2 de la Constitución). Un concepto bien entrado en crisis desde la década de los años 70 del siglo XX, en la que se perdió toda la confianza de que se pudiera cumplir esta función; teniendo el sentir colectivo la percepción de fracaso, ya por las cifras de reincidencia, ya por el tratamiento de los medios de comunicación de la delincuencia, en la que los delincuentes son los otros (los estigmatizados), unos depredadores, que deben ser inocuizaidos. No obstante, el ingreso en prisión provoca en gran parte de los casos sino en todos un proceso de desocialización, por cuanto supone para los condenados la pérdida de capacidades fundamentales de comunicarse y cooperar (Goffman, 1972, p. 26). En primer lugar, el aislamiento del exterior, la sustitución del nombre por un número, el privar a las personas de sus pertenencias, supone para los internos el primer despojo del yo; y cualquier resistencia a las órdenes, provoca el castigo hasta quebrantarla. En una segunda etapa, la imposición de rutinas que les son ajenas, las inspecciones, la continua vigilancia, produce una desidentificación de su yo. Además provoca una ruptura de la relación entre el individuo y sus actos. Así por ejemplo, el fenómeno del looping: un estímulo que origina una reacción defensiva por parte del interno, toma esta misma reacción como objetivo de su próximo ataque. El individuo comprueba que su respuesta defensiva falla en la nueva situación, poniendo cierta distancia entra la situación conflictiva y su yo. 


\subsection{La reclusión en femenino}

La población reclusa femenina en su mayor parte procede de sectores de la sociedad desfavorecidos, donde la pobreza, la marginalidad y la falta de oportunidades han sido unas constantes en sus vidas, además de haber sido víctimas de algún tipo de violencia (Gallizo Llamas, 2010). Las características apuntadas son extrapolables así mismo, a la población reclusa masculina, lo que ocurre, es que la mujer sufre un doble estigma en su origen, las citadas deficiencias estructurales y ser mujer. Yagüe Olmos (2007, pp. 5-7) establece un perfil criminológico de la mujer encarcelada: mujeres supervivientes a una infancia difícil, marginal, carente de oportunidades y afecto; padecen una alta tasa de analfabetismo; ínfima cualificación profesional o experiencia laboral; problemas psíquicos y sobremedicación; pertenecen a minorías desfavorecidas; ausencia de habilidades sociales; autoestima muy baja; ambición y envidia al éxito fácil; dependencia psicológica de la figura masculina; altísima frecuencia de episodios de abusos sexuales y maltrato con relación directa en su historial delictivo; y madre de familia.

La comisión de actos delictivos por parte de las mujeres es casi inexistente si la comparamos con los hechos criminales cometidos por varones. En el año 2016 la población penitenciaria ascendió a 51.029 personas, de las cuales $47.173(92,4 \%)$ son varones, de los que 12.338 son extranjeros, y $3.856(7,6 \%)$ son mujeres, de las cuales 1.046 son extranjeras (SGIIPP, 2017:17). Y si además añadimos que son muy pocos los delitos de carácter violento que se atribuyen al sector femenino de la población penitenciaria, se llega a la conclusión que existe una brecha que acentúa una vez más las diferencias entre hombre y mujer, con perjuicio absoluto para la mujer, ya que al estar invisibilizada de la criminalidad, todo el aparato punitivo es consecuencia de una legislación androcéntrica (Revelles, 2015, p. 155). En este sentido, Almeda (2002, p. 215) manifiesta que la pena privativa de libertad para la mujer es más dura que la de los hombres, además de sufrir situaciones muy discriminatorias. El estudio realizado por Del Val Cid, Viedma y Riviriego (2013) en 42 centros penitenciarios de los 68 existentes apoyan esta afirmación. Así, proporcionalmente hay casi las mismas mujeres $(1,7 \%)$ que varones $(1,9 \%)$ en primer grado (el estadio más grave de cumplimiento de la pena), constituyendo una situación anómala debido a la menor gravedad de los delitos cometidos por mujeres que por hombres; y respecto a las tasas de sanciones graves y muy graves los resultados muestran que las mujeres, en forma proporcional, son más castigadas que los hombres, 3 puntos porcentuales (Del Val Cid, Viedma y Riviriego, 2013, p. 46).

¿Pero por qué existe está gran diferencia? La respuesta hegemónica y normalizada es acudir una vez más al binarismo arraigado en una sociedad patriarcal, que atribuye unos desiguales roles a lo femenino y a lo masculino. Por esta razón, porque tradicionalmente se ha considerado que el espacio del delito no es propio del género femenino, desde los albores de la Criminología, los estudios sobre la mujer delincuente no han despertado un gran interés, salvo algunas excepciones como por ejemplo en The female ofender en 1895, obra en la que Lombroso siguiendo su patrón de explicar al delincuente a través de factores biológicos, considera que la mujer delincuente no contiene ningún rasgo de especificidad, sólo que no había evolucionado hacia el estado propio de la feminidad y le caracterizaban rasgos 
propiamente masculinos, siendo anormales y monstruos. Para Lombroso y Ferrero la mujer criminal es doblemente una excepción, por nacer mujer y por nacer criminal: "Como una doble excepción, consecuentemente, la mujer criminal es un monstruo" (Lombroso y Ferrero, 1895, p. 152). Esta invisibilidad y excepcionalidad de la mujer delincuente no es sino el reflejo y proyección del sesgo de género. Tanto los positivistas como los funcionalistas han sido cuestionados por la criminología crítica, concretamente por la denominada criminología de género, que ofrece nuevas perspectivas, a la vez que "permiten estudiar el enfoque de la política penitenciaria dirigida a las mujeres encarceladas" (Almeda, 2002, p. 218).

Según Juliano (2009, p. 80) "la idea de la que la mujer debe ser naturalmente virtuosa hace que sus transgresiones se evalúen moralmente en mayor medida que la de los hombres". De hecho, las mujeres que trasgredían las normas debían ser sancionadas y readaptadas a la domesticidad, si los hombres de la familia no podían, el Estado se encargaba de ellas, "así las casas galeras" que encerraban a prostitutas, vagabundas y mendigas en el siglo XVII. La rehabilitación para las mujeres consistía en una reprogramación moral, ya que su desviación hasta bien entrado el siglo XX, era considerado pecado más que delito, de hecho las cárceles de mujeres eran administradas por religiosas (Alameda, 2003, citada por Juliano: 2009, p. 83).

Una resocialización, que si para la mujer era volver al ideario de domesticidad y devolverla al ámbito privado bajo la tutela marital o paternal, en términos generales fue una realidad que nunca llegó a consolidarse y que actualmente pese a recogerse como un principio y finalidad de la pena, ya no se cree. De hecho, las políticas punitivistas que imperan en la actualidad, abogan por el endurecimiento de las penas, por una justicia simbólica y por un enclaustramiento del delincuente. Se utiliza a las víctimas en una estrategia de suma cero (si estás con las víctimas no puedes defender las garantías de los penados) prevaliéndose de la fuerza expansiva de los medios de comunicación. Actualmente, el tratamiento penitenciario sigue reforzando el papel tradicional de la mujer en la sociedad, con talleres de corte y confección, tintorería, bordados, cocina, estética, peluquería, etc. Y predominando un enfoque psicoterapéutico, al tener la concepción de la mujer encarcelada como una persona "conflictiva, histérica y emocional", a quien hace falta medicar para controlar su agresividad (Almeda, 2002, p. 229). Cuando en realidad los hombres son los que utilizan formas de desobediencia más conflictivas, mientras que las mujeres se valen más de las quejas o de las ironías.

La discriminación de la mujer en el ámbito penitenciario, la arquitectura penitenciaria, las actividades y la administración, están orientadas por una política androcéntrica "y las presas tienen menos capacidad de presión y conflictividad" (Yague Olmos, 2006). Juliano (2009, p. 84, citando a Ribas Mateos, Alameda y Bodelón, 2005) señala que "las presas disponen de peores instalaciones, están ubicadas más lejos de sus núcleos familiares, cuentan con menos posibilidades de formación y trabajo y cobran por las tareas que realizan en la cárcel mucho menos que los hombres presos". Además, hay que añadir que sufren mayores penas ante iguales delitos, se les reconocen menos atenuantes y más agravantes. Como ye se apuntó, la población penitenciaria femenina constituye un pequeño porcentaje $(7,6)$ del total de personas internas, y la mayoría de las mujeres presas son por delitos no violentos, bien contra la propiedad (hurto, apropiación indebida), bien contra la salud (tráfico de drogas). El Informe General de 2016 de Instituciones Penitenciarias (2017, pp. 24 a 27) señalan que las 
internadas penadas lo son en su mayoría por delitos contra la salud pública $(36,3 \%)$ y contra el patrimonio y el orden socioeconómico (32,5\%). Es decir, por ambos delitos, de carácter no violento, se encuentran en prisión siete de cada diez internas $(68,8 \%)$. Por contra, Los hombres se encuentran en prisión por los siguientes delitos principalmente: contra el patrimonio y el orden socioeconómico $(36,0 \%)$ y contra la salud pública $(21,3 \%)$; a más distancia, los delitos relacionados con violencia de género $(8,5 \%)$; homicidio y sus formas $(7,5 \%)$; contra la libertad sexual $(6,5 \%)$.

El objetivo era que los internos una vez fuera de prisión no volvieran a delinquir, así se cumplía la prevención especial positiva, como finalidad de la pena privativa de libertad. No obstante, los centros penitenciarios no son lugares apropiados para conseguir el objetivo resocializador, de hecho en "Diez razones para no construir más prisiones" de Mathiesen, encontramos argumentos difíciles de refutar, entre otros: la ineficacia de la rehabilitación, la ineficacia preventiva, la ineficacia incapacitadora, la irreversibilidad y no ayuda a las víctimas. Por su parte, Zimbardo (2007) en su libro "El Efecto Lucifer", relata que, cuando le pregunta a un interno que se hallaba cumpliendo condena por robo con fuerza, si cuando salga a la calle volverá a robar, éste le contesta que jamás, que ahora solo pensaba en matar a las personas que le estaban haciendo pasar los padecimientos que sufría en prisión. El tardío y frágil Estado de Bienestar en España y la ausencia de unos servicios sociales específicos dedicados a la prevención de la delincuencia y de la reinserción social, salvo los que dependen orgánicamente de la administración penitenciaria, devienen en el aumento de la población reclusa en general, y femenina en particular (Almeda, 2002, p. 222).

Yagüe Olmos, ex-directora del centro penitenciario de mujeres de Alcalá de Guadaira, plantea una intervención con las internas, que en muchos casos supondrá retomar las primeras fases de socialización, para inculcarles valores primarios como el orden, la puntualidad, la disciplina, para pasar posteriormente y de forma gradual a desenvolverse en el ámbito laboral, trabajar en equipo, etc. Para ello implantó en el centro una combinación de programas de formación, de intervención personal y servicios sociales que "permitan a estas mujeres una mejora en sus capacidades personales y les ayuden a ejercer plenamente sus derechos de ciudadanía" (2007, pp. 7-9).

\subsubsection{Supuestos específicos: mujeres extranjeras y mujeres gitanas}

Históricamente, en el contexto del Derecho Penal, la mujer ha sido considerada como un sujeto sin plena responsabilidad y definida a través de un conjunto de estereotipos sobre su sexualidad (Bodelón, 2003, p. 452). Y es que el sistema de justicia penal, consolida la estructura patriarcal de desigualdad entre hombre y mujer. Afirma Bodelón (2003, p. 466) que "cuando un hombre y una mujer se enfrentan al derecho, no se produce una discriminación porque el derecho se aplique de forma desigual a la mujer, sino porque se aplican criterios aparentemente objetivos y neutrales, pero en realidad responden a un conjunto de valores e intereses masculinos". Los operadores del derecho incorporan a su trabajo y actividad los estereotipos impuestos por el patriarcalismo.

Las mujeres extranjeras sufren mayor discriminación que las nacionales cuando entra en juego el engranaje del sistema penal, y es que, en virtud de la normativa de extranjería se aplican sanciones de expulsión, además de la restricción de derechos fundamentales. Son un colectivo especialmente vulnerable a los procesos sancionadores. La mayoría de las

№ 7, 2019. Página | 149 
extranjeras que ingresan en prisión es un por delito contra la salud pública, son mujeres interceptadas con pequeñas cargas de drogas, utilizadas por redes de narcotraficantes, cuyas sanciones son desproporcionadas e ineficaces porque se crimininalizan en mayor proporción que otros eslabones no tan vulnerables de la red criminal (Bodelón, 2003, pp. 456-458). Sanciones que se cumplen de forma más íntegra, al haberse eliminado del Código Penal de 1995 la redención de penas por el trabajo, que contenía su antecesor el Código Penal de 1973. En definitiva, el sistema penitenciario construido por y para las necesidades de un modelo de sujeto masculino y nacional, se convierte en otro factor de discriminación para las mujeres, y en este caso, las extranjeras. El carecer de arraigo y no tener contacto previo con el país, son algunas de las limitaciones para obtener permisos de salida o el tercer grado.

Por su parte, las mujeres gitanas constituyen el veinticinco por ciento de las internas, siendo el colectivo discriminado más sobrerrepresentado, además de permanecer encerrado un tiempo muy elevado (Equipo Barañí, 2001, pp. 167-172). Sufren una triple discriminación, por ser mujer, por ser gitana y por ser pobre. Y al permanecer tanto tiempo en prisión, la gran mayoría de ellas alcanzan los seis años, el proceso de desadaptación social como consecuencia de estar encerradas, en ellas es más pronunciado al tener hijos y familiares a cargo. Muchas son consumidoras de drogas, por lo que la comisión de sus delitos está altamente relacionado por su adicción, sumado a que para estas mujeres no existen alternativas reales a la cárcel. El Equipo Barañí (2001, p. 173) señala por ejemplo que "será difícil que puedan acogerse a la suspensión de la condena prevista en el Código Penal, pues las penas asociadas a los delitos por los que cumplen condena, normalmente superan con creces el límite previsto para acogerse a este beneficio".

En el ámbito de la justicia de menores, las mujeres también sufren discriminación. Es clarificador como "los profesionales consideran que las chicas con problemas tienen problemas sexuales" (Bodelón, 2003, p. 463), una prueba más de como la sexualidad sigue siendo la piedra angular de las estrategias patriarcales y el barómetro utilizado para medir su adecuación a los códigos sociales.

\section{Conclusiones}

Los códigos, los reglamentos, las leyes, han surgido tras un proceso consensuado y acordado, y es fácil de alegar su existencia y vigencia. En cambio, las normas entendidas como usos sociales y no como normas jurídicas, funcionan como pautas de conductas aprobadas por la sociedad, debido a la reiteración de las mismas y aceptadas e interiorizadas por todos sus miembros. Actúan de forma implícita y de ahí la fuerza que las envuelve, ya que no existe ningún texto que las recoja y que pueda ser refutado o cuestionado. Se convierten en los parámetros de la normalidad, del espacio que alberga a las personas que se aceptan como sujetos de derecho y por ende como sujetos aprobados por la sociedad. Una sociedad que reserva un espacio de abyección para aquellos que se alejan de las normas, marginándolos, excluyéndolos y discriminándolos. Pero la mayor fuerza que llegan a poseer estas normas, es que convierten comportamientos, conductas y actitudes en naturales, que de por sí no lo son. Naturalizan productos culturales y los tachan de inmutables, completamente impermeables al cambio o al menos a la reflexión. En estas condiciones la educación se convierte en la estrategia fundamental para deconstruir este paradigma de exclusión que es la sociedad patriarcal. 
I. El paradigma del estigma, creado por la sociedad patriarcal, que naturaliza la desigualdad de poder a través de medios coercitivos y como un continuo, cuya máxima expresión es la violencia de género, es una construcción social, definida por los sujetos dominadores en un tiempo y espacio concreto. Cuando se habla de violencia de género, el artículo 1 de la Ley 1/2004 establece que se entiende por violencia de género aquella "violencia que, como manifestación de la discriminación, la situación de desigualdad y las relaciones de poder de los hombres sobre las mujeres"; quedando, por tanto las relaciones entre parejas del mismo sexo al margen de esta definición jurídica. La subordinación de la mujer, económica, social, laboral y legal, se alcanzó a lo largo de los siglos, con el Derecho masculinista, medidas provenientes del aparato estatal, complementado y sustentado por la defensa de unos valores que relegaban a la mujer a la esfera doméstica, al culto a la maternidad y a la ética del cuidado.

II. La desviación, definida como la transgresión de las normas (sociales) vigentes, no es una atribución de la conducta, sino una característica arrogada a las personas mediante procesos de exclusión. La criminalidad es creada por el control social, que la genera al definir como delito un determinado comportamiento. El riesgo de ser etiquetado como delincuente no depende tanto de la conducta ejecutada como del rol de la persona en la jerarquía social. La pena potencia y perpetúa la desviación, consolida al desviado en su rol de delincuente. La mujer es el sujeto dominado en la sociedad patriarcal, y aquella que se rebela contra las pautas impuestas por la misma, deviene en sujeto estigmatizado. La estigmatización conduce a la exclusión y desviación y de ahí un paso a la criminalización, al internamiento y reclusión. Con la consiguiente pérdida o disociación de su propia identidad, a través de un aprendizaje distorsionado, acepta la nueva identidad impuesta por la maquinaria punitiva e institucional. Se redefinirá en torno al rol de delincuente.

III. La población reclusa femenina, casi inexistente si la comparamos con la población masculina, en su mayor parte procede de sectores de la sociedad desfavorecidos, donde la pobreza, la marginalidad y la falta de oportunidades han sido unas constantes en sus vidas, además de haber sido víctimas de algún tipo de violencia. Las mujeres en prisión sufren la pena de forma más gravosa que el hombre, como consecuencia de que todo el aparato punitivo es consecuencia de una legislación androcéntrica; así como por saltarse las normas de género, no ha sabido ajustarse a vivir la situación que le toca como mujer. La discriminación en la criminalización de la mujer operaría en tres fases: en el ámbito normativo, que tras múltiples vicisitudes no se daría, pues el derecho positivo garantiza la igualdad; durante el proceso penal, donde pueden producirse sesgos consecuencia de las características de la mujer (ya sean por nivel adquisitivo, etnia, etc.), que no les permite un igual acceso a los medios jurídicos; y por último, pero no menos importante, las discriminaciones que se producen en prisión por etiquetamiento de las infractoras.

IV. Es imprescindible para todos los profesionales que desarrollen su actividad de cara a la ciudadanía, ya sean como docentes, como operadores jurídicos, como trabajadores sociales o personal sanitario, entre otros, la formación en estudios de género. Ahondar en las raíces de esta forma específica de dominación que constituye una auténtica lacra social, lo cual nos permite comenzar a desarticular las bases sobre la que se estructura. Hay que abordar el cambio en todas sus dimensiones, y no desde el punto reduccionista que nos da los medios de comunicación de masas e incluso las propias instituciones. Esta formación se conforma 
como un mandato para los poderes públicos, como así recoge el artículo 15 de la Ley 3/2007: "el principio de igualdad de trato y oportunidades entre mujeres y hombres informará, con carácter transversal, la actuación de todos los Poderes Públicos. Las administraciones públicas lo integrarán, de forma activa, en la adopción y ejecución de sus disposiciones normativas, en la definición y presupuestación de políticas públicas en todos los ámbitos y en el desarrollo del conjunto de todas sus actividades". Supone la implantación de la estrategia de la transversalidad de género (mainstreaming de género) (Consejo de Europa, 1998), por la que se incorpora una perspectiva de igualdad de género en todos los niveles y fases de todas las políticas, para lograr un cambio estructural y social.

\section{Referencias}

Almeda, Elisabet (2002). Corregir y castigar. El ayer y hoy de las cárceles de mujeres, Barcelona: Bellaterra.

Bodelón, Elena (2003). Género y sistema penal: los derechos de las mujeres en el sistema penal. En Roberto Bergalli (coord.): Sistema penal y problemas sociales. Valencia:Tirant lo Blanch.

Bonino Méndez, Luis (1999). Desvelando los micromachismos en la vida conyugal. En Jorge Corsi et al., Violencia masculina en la pareja. Buenos Aires: Paidós.

Butler, Judith (2007). El género en disputa. Barcelona: Paidós.

Christie, Nils (2004). Una sensata cantidad de delito. Buenos Aires: Editores del Puerto.

Consejo de Europa (1998). Mainstreaming de género. Marco conceptual, metodología y presentación de "buenas prácticas". Informe final de las actividades del Grupo de especialistas en mainstreaming (EG-S-MS). Recuperado de: https://bit.ly/2mZHW9B.

Coy, Ernesto y Martínez, $\mathrm{M}^{\mathrm{a}}$ del Carmen (1988). Desviación social: una aproximación a la teoría y la intervención. Murcia: Secretariado de Publicaciones de la Universidad de Murcia.

Del Val Cid, Consuelo, Viedma, Antonio y Reviriego, Fernando (2013). Hacia una medida objetiva de la discriminación en la cárcel: indicadores e índice de punición, en Revista Criminalidad, Vol. 55 (2). Recuperado de: https://bit.ly/2Pfujk9.

Engels, Fiedrich (2013). El origen de la familia, la propiedad privada y el Estado. Madrid: Alianza Editorial.

Equipo Barañí (Hernández, Imaz, Martín, Naredo, Pernas, Tandogán y Wagman) (2001): Mujeres gitanas y sistema penal. Recuperado de: https://bit.ly/2PgpK9u.

Facio, Alda y Fries, Lorena (2005). Feminismo, género y patriarcado. En Academia: Revista sobre enseñanza del Derecho de Buenos Aires, Año 6, núm. 6. Recuperado de: https://bit.ly/2N3q6Ty.

Gallizo Llamas, Mercedes (2010). Las cárceles y los derechos humanos. En Página Abierta, $\mathrm{n}^{\mathrm{o}}$ 207. Recuperado de: https://bit.ly/2LzzAB6.

García Meseguer, Álvaro (1977). Lenguaje y discriminación sexual. Madrid: Cuadernos para el diálogo.

- (1994). ¿Es sexista la lengua española?, Barcelona: Paidós.

Gayle, Rubin (1986): El tráfico de mujeres. Notas sobre la economía política del sexo. En Nueva Antropología, Vol. VIII, $\mathrm{n}^{\circ}$ 30, México: UNAM. Recuperado de: www.redalyc.org/pdf/159/15903007.pdf. 
Goffman, Erving (1972). Internados. Ensayos sobre la situación social de los enfermos mentales. Buenos Aires: Amorrortu.

- (1998). Estigma. La identidad deteriorada. Buenos Aires: Amorrortu.

Juliano, Dolores (2004). Excluidas y marginales. Madrid: Cátedra.

- (2009). Delito y pecado. La transgresión en femenino. En Política y sociedad, Vol. $\quad 46, \mathrm{n}^{\mathrm{o}}$ 1, enero-abril. Recuperado de: https://bit.ly/2PLok7K.

Lamo de Espinosa, Emilio (1989). Delitos sin víctima. Orden social y ambivalencia moral. Madrid: Alianza Universal.

Lees, Sue (1994). Aprender a amar. Reputación sexual, moral y control social de las jóvenes. En Elena Larrauri (ed.) Mujeres, Derecho Penal y Criminología, Madrid: Siglo Veintiuno.

León-Mejía, A. (2006). Feminismo disidente: un acercamiento a las posiciones críticas con el feminismo establecido desde la documentación y el análisis de la producción científica, Informe IESA Working Paper Series WP 15-06. Consejo Superior de Investigaciones científicas. Recuperado de: http://digital.csic.es/handle/10261/2066.

Lerner, Gerda (1990). La creación del patriarcado. Barcelona: Crítica.

Lombroso, Cesare y Ferrero, Guglielmo (1895). The female ofender. California: Rothman and Company.

Malinowski, Bronislaw (1984). Una teoría científica de la cultura. Madrid: Sarpe.

Marqués, Josep-Vicent (1990): La construcción social del varón. En Josep-Vicent Marqués y Raquel Osborne, Sexualidad y sexismo, Parte primera: Varón y patriarcado, Madrid: Fundación Universidad-Empresa.

Mathiesen, Thomas (2004). Diez razones para no construir más cárceles. En Jornadas Prison, Londres. Recuperado de: https://bit.ly/2BXGReg.

Mestre i Mestre, Ruth y López Precioso, Magdalena (2006). Trabajo sexual. Reconocer derechos. Valencia: Ediciones Burbuja.

Ministerio de Sanidad, Asuntos Sociales e Igualdad (2015). Conferencia Sectorial de Igualdad, Madrid.

Nash, Mary (1989). Control social y trayectoria histórica de la mujer en España. En R. Bergalli y E. Mari (coords.), Historia ideológica del control social. Barcelona: PPU.

Orwell, George (2010). 1984, Barcelona: Austral.

Parlamento Europeo (2014). Resolución del Parlamento Europeo, de 26 de febrero, sobre explotación sexual y prostitución y su impacto en la igualdad de género. Recuperado de: https://bit.ly/2N0QAoo.

Revelles Carrasco, María (2015). La violencia y las mujeres en prisión. En Derecho Penal, Género y Nacionalidad. Granada: Comares.

Secretaría General de Instituciones Penitenciarias (2017). Informe General 2016, Ministerio del Interior, Madrid. Recuperado de: https://bit.ly/2Ph0MH7.

Yagüe Olmos, Concepción (2007). Mujeres en prisión. Intervención basada en sus características, necesidades y demandas". En Revista Española de Investigación Criminológica, Artículo 4, no 5. Recuperado de: https://bit.ly/2NqnUSY.

Zimbardo, Philip (2007). El efecto Lucifer. Barcelona: Paidós. 